\title{
EVOLUÇÃO DO NÍVEL DE CONCENTRAÇÃO E PRODUÇÃO DA SOJA NO BRASIL E MATO GROSSO DO ANO 2000 A 2010
}

\author{
Keite Soares Gazola ${ }^{1}$ \\ Laércio Juarez Melz ${ }^{2}$ \\ Ariel Lopes Torres ${ }^{3}$ \\ Karine Medeiros Anunciato ${ }^{4}$
}

\section{RESUMO}

A pesquisa teve como objetivo apresentar a concentração da produção de soja nos estados brasileiros, nas microrregiões do Brasil , nas microrregiões e nos municípios do estado de Mato Grosso. Foram coletados dados no IBGE para fazer as analises. A análise foi feita entre os anos de 2000 a 2010, observando a área planta, área colhida e produção do Brasil e do Mato Grosso. Foi adaptado um índice de concentração, a razão de concentração (CR). Os resultados apontaram desconcentração regional da produção nos municípios do estado de Mato Grosso e concentração nos estados brasileiros. Os estados mantiveram os quatro maiores produtores entre 2000 e 2010 houve desconcentração da produção, os 12 maiores produtores representam em 2010 98\% da produção brasileira. Nas microrregiões Brasileiras houve desconcentração de produção. Houve uma significativa desconcentração espacial da produção de soja nos municípios devido alguns pequenos municípios que vieram a se destacar com um aumento de produção dentre esses anos analisados considerando a distribuição entre as cidades, como Ipiranga do Norte que em 2006 passou a fazer parte dos dezesseis maiores produtores com $3 \%$ da produção do estado do Mato Grosso.

Palavras-chaves: Concentração espacial. Produção da soja. Razão de concentração.

\section{INTRODUÇÃO}

A produção da soja é das atividades econômicas com crescimento mais significativo dentro do agronegócio nacional e internacional. Pode-se atribuir essa evolução a diversos fatores, tais como: o desenvolvimento e estruturação de um mercado sólido internacional, a produção de diversificados produtos derivados da soja e a viabilização de exportação desta leguminosa para várias regiões do mundo (EMBRAPA, 2010).

A soja é um dos grãos mais produzido em escala mundial, com área plantada de 103,5 milhões de hectares em 2011, e essa produção está concentrada principalmente nos países da América. (EMBRAPA, 2012).

\footnotetext{
${ }^{1}$ Acadêmica de Ciências Contábeis da UNEMAT campus de Tangará da Serra, e-mail: keitesgazola@gmail.com

2 Mestre em Engenharia de Produção (UFSCar), Professor de Ciências Contábeis da UNEMAT campus de Tangará da Serra, e-mail: laercio@unemat.br

${ }^{3}$ Mestre em Administração e Finanças (UNEX), Professor de Ciências Contábeis da UNEMAT campus de Tangará da Serra, e-mail: ariel@unemat.br

${ }^{4}$ Mestre em Agricultura Tropical (UFMT), Professor de Ciências Contábeis da UNEMAT campus de Tangará da Serra, e-mail: karine@unemat.br 
Evolução do nível de concentração e produção da soja no Brasil e Mato Grosso do ano 2000 a 2010

Keite Soares Gazola

Laércio Juarez Melz

Ariel Lopes Torres

Karine Medeiros Anunciato

O maior produtor individual de soja é os Estados Unidos, sua produtividade média é de $35 \%$, e exportação de $40 \%$, em seguida vem o Brasil com $25 \%$ de produção e uma exportação igual a dos Estados Unidos, lembrando que esses percentuais estão relacionados aos outros países produtores desta leguminosa (MERCOPRESS, 2011).

A Argentina é a principal exportadora do óleo de soja, os demais produtores do grão na América são: Uruguai, Canadá, Paraguai e Bolívia. China e Índia, entre os países asiáticos, estão na quarta e quinta colocações, respectivamente (MERCOPRESS, 2011).

Em 1999 os países do Mercosul tinham 26 milhões de hectares plantados com a soja, hoje as áreas plantadas estão acima de 49 milhões. A América Latina poderá aumentar sua produção em cerca de mais 50 milhões de toneladas até 2020, conforme afirmou Fabio Trigheirinho da Associação Brasileira da Indústria de Óleos Vegetais (ABIOVE, ANO).

Segundo os participantes do Congresso da Soja (MERCOSOJA), composto pelos países que formam o Mercosul, estes foram responsáveis por 136 milhões de toneladas colhidas em 2011 e pode-se afirmar que 52,31\% da colheita corresponde aos países do Mercosul, em seguida, os Estados Unidos com 83 milhões de toneladas colhidas. O total da colheita mundial em 2011 foi de 260 milhões de toneladas, (MERCOPRESS, 2011).

O Brasil possui uma grande participação na oferta da soja, isso vem exercendo um papel de suma importância para o desenvolvimento de varias regiões do país. Em 2001/2002, o país figurava como o segundo produtor do grão em escala mundial, responsável por 23,5\% das 184 milhões de toneladas produzidas mundialmente (EMBRAPA, 2003).

Embora a área plantada com a oleaginosa represente apenas 7,65\% da agricultura brasileira (CONAB, 2010; IBGE, 2010), as exportações de produtos derivados deste grão representaram aproximadamente 26,64\% das exportações do agronegócio do país (BRASIL, 2010).

Desde a década de 70 o cerrado brasileiro atua como fronteira nacional de produção, é visto como o grande potencial do país, devido a seu crescimento nos últimos anos e cerca de 50\% da produção nacional do grão está nas áreas de cerrado (ECOA, 2003).

Algumas regiões do país como Centro Norte, Centro Oeste, Nordeste, Noroeste e Centro Leste são chamados de corredores de exportação, assim como também as hidrovias Araguaia-Tocantins e Paraguai-Paraná (ECOA, 2001).

Mato Grosso vem se destacando no cultivo da soja, entre os estados brasileiros, a safra 2010/2011 teve uma produção de 20 milhões de toneladas, cerca de $3.190 \mathrm{~kg} / \mathrm{ha}$., de acordo 
Evolução do nível de concentração e produção da soja no Brasil e Mato Grosso do ano 2000 a 2010

Keite Soares Gazola

Laércio Juarez Melz

Ariel Lopes Torres

Karine Medeiros Anunciato

com a Associação de produtores de soja do Estado do Mato Grosso (APROSOJA), a produção do estado chegara a 21 milhões de toneladas em 2012.

O estado vem sendo comparado a um país emergente, e isto trás bons resultados para a dinâmica da economia local e contribui para o bom desempenho de importantes indicadores nacionais. Segundo o economista Carlos Vitor Timo Ribeiro, hoje o agronegocio brasileiro responde por quase um terço do Produto Interno Bruto (PIB) do Brasil (IMA/MT,2012).

Foi realizado um levantamento, pela consultora Deloitte, a fim de identificar os novos centros de desenvolvimento no interior do Brasil, e a consultora pode observar, com base nos dados do IBGE, que o norte e sudeste mato-grossense, principalmente as cidades de Primavera do Leste e Sorriso, destacam na produção de grãos e na agroindústria. Sorriso desponta como a maior área plantada com soja no mundo, são mais de 600 mil hectares. Outras cidades também são citadas como Lucas do Rio Verde e Nova Mutum (PEREZ, 2012).

Conforme dados do Instituto Mato-grossense de Economia e Agropecuária (IMEA), o norte do Mato Grosso produz 45,66\% da soja produzida no estado, enquanto o sudeste corresponde a $22,91 \%$. Juntos têm uma produção de mais de $68 \%$ da oleaginosa no estado. Considerando a expectativa, as duas regiões sozinhas, na safra 2011/2012, deverão atingir a 15,26 milhões de toneladas. A estimativa é que o estado torne-se o $5^{\circ}$ maior produtor mundial, sendo responsável por 21,44\% do volume nacional (Perez, 2012).

De acordo com o exposto, a pergunta problema desta pesquisa foi: Os níveis de concentração da produção de soja nos estados e nas microrregiões brasileiras, nas microrregiões e nos municípios do Mato Grosso tiveram aumento entre 2000 e 2010 ?

A hipótese levantada foi de que a entrada de novos municípios na produção de soja no estado fez com que a produção se desconcentrasse entre 2000 e 2010.

A partir desta problematização, o objetivo da pesquisa foi verificar qual o nível de evolução e concentração na produção de soja entre os estados Brasileiros, as microrregiões do Brasil e do Mato Grosso e os municípios do Mato Grosso nos anos de 2000 a 2010.

Foram estabelecidos os objetivos específicos: 1. Apresentar a evolução da concentração regional da produção de soja entre os estados brasileiros; 2. Apresentar a evolução da concentração regional da produção de soja entre as microrregiões brasileiras; 3. Apresentar a evolução da concentração regional da produção de soja entre as microrregiões de Mato Grosso; 4. Apresentar a evolução da concentração regional da produção de soja entre os municípios de Mato Grosso. 


\section{REFERENCIAL TEÓRICO}

\subsection{Histórico da produção de soja no mundo}

Para melhor entender a evolução da soja é preciso contar sua história. A palavra soja vem do japonês shoyu. É uma planta originária do extremo oriente e não há um consenso sobre qual país iniciou seu cultivo, contudo, ela é cultivada há milênios em paises como a China, o Japão, a Indonesia e a Manchuria, sendo uma das bases da alimentação do seu povo (EMPRAPA, 2003).

A soja originalmente é uma planta rasteira que se desenvolvia na costa leste da Ásia, principalmente ao longo do Rio Yangtse, na China. Sua evolução começou com o aparecimento de plantas oriundas de cruzamentos naturais entre duas espécies de soja selvagens que foram melhoradas por cientistas na antiga China. Sua importância na dieta alimentar da antiga civilização chinesa era tanta, que a soja foi considerada um grão sagrado, com direito a cerimoniais e rituais no plantio e na colheita (EMPRAPA, 2003).

Os primeiros registros de preparo doméstico utilizando o grão foram o queijo e o molho, conhecidos em todo o mundo como Tofu e Shoyo. Há também a farinha, o leite e outros derivados da soja que já são mundialmente consumidos (NUTRISOY, 2012).

Entre o final do século XV e começo do século XVI, com a chegada de navios europeus, a soja, foi levada para a Europa e lá permaneceu como curiosidade até aproximadamente no começo do século XX. Os Estados Unidos (EUA) iniciaram sua exploração comercial, primeiro com a forrageira e, posteriormente, o grão. Na segunda década do século $\mathrm{XX}$, as proteínas do grão começaram a despertar interesses das indústrias mundiais. No auge do seu cultivo foram plantados nesse país cerca de dois milhões de hectares. A partir de 1941 a área plantada, com a oleaginosa, para consumo humano superou a cultivada para forragem, que entrou em declínio até desaparecer (EMPRAPA, 2003).

A leguminosa possui aproveitamento dietoterápico, que está paralelo às técnicas de engenharia alimentar. A evolução dos costumes e hábitos nutricionais foram os responsáveis pela evolução de aproveitamento da soja. Até certo tempo a soja era consumida apenas por vegetarianos. 
Evolução do nível de concentração e produção da soja no Brasil e Mato Grosso do ano 2000 a 2010

Keite Soares Gazola

Laércio Juarez Melz

Ariel Lopes Torres

Karine Medeiros Anunciato

É usada, também, na indústria de confecções, indústria de adesivos e nutrientes, adubos, formulador de espumas, fabricação de fibras, revestimento, papel, emulsão de água para tintas, setor de combustíveis, compostos nutritivos e em vários outros segmentos industriais razão da expansão mundial foi devido aos aumentos de área e também pelos aumentos de rendimento que foram sendo melhores graças ao conhecimento científico gerados rapidamente e repassado aos agricultores (FEDERIZZI, 2012).

Das poucas toneladas produzidas no inicio dos anos 20 até 219 milhões de toneladas de grãos de soja estimadas para a safra 2005/2006 se criaram muitas oportunidades e um mercado em crescimento com demandas ainda maiores (FEDERIZZI, 2012).

As políticas internas de agricultura e comércio de cada país foram assumidas para continuar a evoluir ao longo de suas trajetórias, com base no julgamento dos analistas do United States Department of Agriculture (USDA). Em particular, muitos países em desenvolvimento assumiram compromisso com a continuidade das reformas econômicas e comerciais. Do mesmo modo, o desenvolvimento e a utilização de tecnologia, para acompanhar e oferecer novos produtos nas preferências dos consumidores, visando continuar a evoluir com base no desempenho passado e julgamentos a respeito das análises futuras.

Em 1904 o químico americano G.W. Carver descobriu que a soja é fonte de proteína e óleo. Os primeiros relatos tanto nos Estados Unidos como na Argentina e Brasil ressaltavam a qualidade do grão de soja que poderiam ser utilizados para muitos fins industriais (Boerger, 1943). A composição aproximada dos grãos de soja é: Proteínas (40\%), Óleo (20 \%), Celulose (17\%), Açúcares (7\%), Cinzas (6\%), Fibra (5\%) e outros (5\%) (FEDERIZZI, 2012).

A soja é a grande responsável pela profissionalização e especialização da agricultura, e por volta dos anos 60 em algumas regiões do Brasil também foi responsável pela introdução do conceito de agronegócio devido a quantidade de investimentos (MARAFON, 1998).

Segundo os relatos de Millán (1935):

Sementes de soja já eram distribuídas aos produtores em 1882 e até 1930 haviam sido publicadas 23 comunicações técnicas sobre a cultura. O folheto número 871 do Ministério de Agricultura de la Nacion de Buenos Aires (1931) apresentava os dados de proteína e óleo da soja em comparação com outras leguminosas e demonstrava as possibilidades da soja para alimentação humana.

Inúmeros trabalhos têm sido dirigidos em todo o mundo para analisar problemas e propor alternativas que aumentem a competitividade de sistemas agroindustriais específicos. 


\subsection{Medidas de concentração}

As medidas de concentração são muito empregadas para indicar como é a estrutura de um determinado mercado. Neste texto são discutidas algumas medidas de concentração utilizadas pelos diversos órgãos de diferentes países. Estas medidas se dividem em dois grupos: as razões de concentração e os índices de concentração (SCHMIDT, 2002).

\section{Conforme Braga e Mascolo (1982)}

Em um sentindo amplo, concentração significa acumulação de certos atributos econômicos (tais como renda, riqueza, produção, etc.) por correspondentes unidades de controle (indivíduos, firmas, estabelecimentos industriais).

Bain (op. cit.: 103) conceitua concentração como:

Propriedade ou controle de uma grande proporção de agregados de recursos econômicos ou de atividades, tanto por uma pequena proporção das unidades que possuem ou controlam os agregados, quanto por um pequeno número destas unidades.

Por outro lado, a concentração industrial, na visão de Labini (1980), trata-se fundamentalmente de um processo dirigido à busca de crescente eficiência técnica e econômica.

Para Boyle (apud Brumer, 1981):

De uma maneira simplificada, a concentração, em sua forma mais simples, representa um método de descrição pelo qual $n$ empresas controlam $x$ por cento das vendas, da capacidade produtiva, dos lucros, ou de alguma outra variável.

Resende (1994) ressalta que:

A utilização de índices de concentração, tenta-se resumir em um único indicador um conceito com múltiplas dimensões, o que indica a necessidade de análises complementares ao calculo de índices de concentração.

O índice razão de concentração é utilizado para medir, proporcionalmente, número fixo de produção da empresa, em relação as demais empresas, tornando-se base do indicador escolhido. Segundo Resende e Boff (2002) “A razão de concentração de ordem $k$ é um índice positivo que fornece a parcela de mercado das $k$ maiores empresas da indústria”.

Seu cálculo é dado por: 


$$
\operatorname{Cr}(k)=\sum_{i=1}^{k} P_{i}
$$

Onde:

$k=$ número de cidades que fazem parte do cálculo;

$P i=$ participação da i-ésima da produção no estado.

Isto é, $P_{i}=Y_{i} /\left(S_{i=1}^{n} Y_{i}\right)$.

Quanto maior for o valor do índice, maior é o poder de mercado exercido pelas $\mathrm{k}$ maiores empresas. Para Resende e Boff (2002) "nas aplicações empíricas, toma-se comumente $k=4$ ou $k=8$, isto é, considera-se apenas a participação das quatro ou das oito maiores empresa."

\section{METODOLOGIA}

A pesquisa na agricultura torna-se gigantesca se não delimitado o espaço de análise. $\mathrm{O}$ produto analisado foi a produção da soja e a dimensão geográfica demarcada são os Estados, as microrregiões do Brasil, as microrregiões e municípios do estado de Mato Grosso, sendo avaliado o período de 2000 a 2010. Este trabalho teve como base o método científico de pesquisa, a forma de estudo foi a descritiva e foi utilizada a abordagem quantitativa e o método comparativo.

De acordo com Beuren (2003, p.80), a caracterização da pesquisa descritiva:

[...]a pesquisa descritiva tem como principal objetivo descrever características de determinada população ou fenômeno ou o estabelecimento de relações entre as variáveis. Uma de suas características mais significativas está na utilização de técnicas padronizadas de coletas de dados.

Beuren (2003, p.92) complementa que:

Na pesquisa qualitativa concebem-se análises mais profundas em relação ao fenômeno que está sendo estudado. A abordagem qualitativa visa destacar características não observadas por meio de um estudo quantitativo, haja vista a superficialidade deste último.

Nesta pesquisa foram utilizados os índices de razão de concentração CR4, CR8 e CR16, conforme Marques (1994). Os dados da pesquisa foram coletados na base de dados SIDRA do Instituto Brasileiro de Geografia e Estatística (IBGE). Foi realizado um levantamento da produção anual dos estados brasileiros, das microrregiões do país e do estado do Mato Grosso e das cidades do estado de Mato Grosso entre os anos 2000 e 2010 . O 
Evolução do nível de concentração e produção da soja no Brasil e Mato Grosso do ano 2000 a 2010

Keite Soares Gazola

Laércio Juarez Melz

Ariel Lopes Torres

Karine Medeiros Anunciato

número de unidades da federação, microrregiões e municípios podem ser observados na Tabela 1.

Tabela 1. Regiões consideradas para análise dos índices.

\begin{tabular}{cc}
\hline Região considerada para cálculo & Quantidade \\
\hline Estados brasileiros + Distrito federal & 27 \\
Microrregiões no Brasil & 289 \\
Microrregiões em Mato Grosso & 22 \\
Municípios em Mato Grosso & 141 \\
\hline
\end{tabular}

Aos índices de concentração foram impostas classificações de acordo com os percentuais de participação dos quatro e oito maiores atuantes do mercado, adaptados de Medeiros e Ostroski (2006), demonstrados no quadro 1. Essa classificação foi utilizada para análise dos dados.

Quadro 1 - Nível de concentração de mercado a partir da análise da razão de concentração (CR).

\begin{tabular}{|lcc|}
\hline \multicolumn{1}{|c|}{ Níveis de mercado } & Razão de Concentração \\
Altamente concentrado & $\mathrm{i}>75 \%$ & CR8 \\
Alta concentração & $65 \%<\mathrm{i}<75 \%$ & $\mathrm{i}>90 \%$ \\
Concentração moderada & $50 \%<\mathrm{i}<65 \%$ & $85 \%<\mathrm{i}<90 \%$ \\
Baixa concentração & $35 \%<\mathrm{i}<50 \%$ & $70 \%<\mathrm{i}<85 \%$ \\
Ausência de concentração & $\mathrm{i}<35 \%$ & $45 \%<\mathrm{i}<70 \%$ \\
Claramente atomístico & $=2 \%$ & $\mathrm{i}<45 \%$ \\
\hline
\end{tabular}

Fonte: Medeiros e Ostroski (2006).

\section{RESULTADOS E DISCUSSÃO}

Foram estabelecidos indicadores de concentração considerando o aumento de produção dos estados, microrregiões do Brasil e nos municípios e microrregiões do estado de Mato Grosso. A análise desses indicadores está apresentada nos quadros a seguir.

\subsection{Evolução da concentração da soja nos estados Brasileiros.}

A cultura agrícola que mais cresceu entre 1960 e 2010 foi soja, que corresponde a $49 \%$ da área plantada em grãos no país. Esse aumento está associado aos avanços tecnológicos, ao manejo e eficácia dos produtores. Cultivada principalmente nas regiões Centro Oeste e Sul do país, a soja tornou-se o produtos com mais destaque na agricultura nacional e na balança comercial (ÁVILA, 2011). A evolução da produção nesses dez anos foi considerável, passando de 32.820 .826 em 2000 para 68.765 .343 em 2010. Um aumento de $110 \%$ na 
Evolução do nível de concentração e produção da soja no Brasil e Mato Grosso do ano 2000 a 2010

Keite Soares Gazola

Laércio Juarez Melz

Ariel Lopes Torres

Karine Medeiros Anunciato

quantidade produzida entre 2000 e 2010. Ao analisar os dados da concentração da produção de soja por estado é possível notar que existe uma tendência de concentração em determinados estados do Brasil (Tabela 2). Entre 2000 e 2003, a produção de soja entre os estados foi 'altamente concentrada', conforme classificação de Medeiros e Ostroski (2006). A partir de 2004 a produção entre os estados passou a ser de 'alta concentração'. Considerando os oito maiores (CR8) apresenta-se nível 'altamente concentrado' em todos anos analisados, de acordo com a classificação de Medeiros e Ostroski (2006). Entre os oito e os doze maiores existia em 2010 diferença de 5\% da produção. Os últimos 10 estados no ranking representaram somente $2 \%$ da produção de soja, em 2010.

Tabela 2. Evolução da concentração da produção da soja por estados Brasileiros.

\begin{tabular}{|c|c|c|c|c|c|c|c|c|c|c|c|}
\hline Índice & 2000 & 2001 & 2002 & 2003 & 2004 & 2005 & 2006 & 2007 & 2008 & 2009 & 2010 \\
\hline CR4 & $76 \%$ & $77 \%$ & $77 \%$ & $77 \%$ & $73 \%$ & $72 \%$ & $73 \%$ & $74 \%$ & $73 \%$ & $74 \%$ & $74 \%$ \\
\hline CR8 & $96 \%$ & $96 \%$ & $97 \%$ & $96 \%$ & $94 \%$ & $93 \%$ & $93 \%$ & $93 \%$ & $92 \%$ & $92 \%$ & $93 \%$ \\
\hline CR12 & $99 \%$ & $99 \%$ & $99 \%$ & $99 \%$ & $97 \%$ & $97 \%$ & $97 \%$ & $97 \%$ & $96 \%$ & $97 \%$ & $98 \%$ \\
\hline
\end{tabular}

Houve concentração da produção de soja entre os anos 2000 e 2003, nos estados de Mato Grosso, Paraná, Rio Grande do Sul e Goiás (Tabela 3). Mato Grosso foi o estado que mais cresceu em participação na produção de soja neste período, em 2000 representava $27 \%$ da produção e no ano de 2005 esse percentual chegou a 35\%, de participação no mercado. O Rio Grande do Sul é o terceiro maior produtor de soja do Brasil, de acordo com a Tabela 2, essa posição que ocupa anos 2001 a 2003, com média de produção de 16,8\%. Essa participação tem oscilado, cresceu de forma lenta no início e teve uma retração no em 2005, perdendo espaço para Goiás, como demonstram os dados de média do período 2004 a 2005 na Tabela 3.

Analisando os anos de 2000 a 2010 verificou-se que houve uma redução na produção do estado do Paraná sua participação passou de 22\% em 2000, para 20\%, em 2010 (Tabela 3).

A observação dos indicadores revelou que houve desconcentração da produção, quando examinado em nível de estados. Em 2000, os quatro maiores estados produtores representavam 76\% da produção e passaram em 2010 para $74 \%$ de participação na produção do País. Percebeu-se que a produção de Mato Grosso, maior produtor, representa quase o dobro da produção do Rio Grande do Sul, terceiro maior (Tabela 3).

Entre os oito e os doze maiores pode-se verificar que apenas em São Paulo houve queda de produção. No ano de 2000, o estado representava $4 \%$ da produção nacional e em 2010 esse percentual diminuiu para 2\%, os demais estados mantiveram suas produções estáveis (Tabela 3). 
Evolução do nível de concentração e produção da soja no Brasil e Mato Grosso do ano 2000 a 2010

Keite Soares Gazola

Laércio Juarez Melz

Ariel Lopes Torres

Karine Medeiros Anunciato

Tabela 3. Identificação dos doze maiores estados produtores de soja do Brasil, 2000-2010, em mil toneladas,

\begin{tabular}{cccccccccccccc}
\multicolumn{10}{c}{2000 e 2010 em \%. } \\
\hline UF & 2000 & $\%$ & 2001 & 2002 & 2003 & 2004 & 2005 & 2006 & 2007 & 2008 & 2009 & 2010 & $\%$ \\
\hline BR & 32.821 & 100 & 37.907 & 42.108 & 51.919 & 49.550 & 51.182 & 52.465 & 57.857 & 59.833 & 57.345 & 68.756 & 100 \\
MT & 8.774 & 26,7 & 9.533 & 11.685 & 12.966 & 14.518 & 17.761 & 15.594 & 15.275 & 17.803 & 17.963 & 18.788 & 27,3 \\
PR & 7.188 & 21,9 & 8.615 & 9.539 & 11.010 & 10.219 & 9.492 & 9.363 & 11.877 & 11.800 & 9.409 & 14.092 & 20,5 \\
RS & 4.784 & 14,6 & 6.952 & 5.611 & 9.579 & 5.542 & 2.445 & 7.559 & 9.929 & 7.680 & 8.025 & 10.480 & 15,2 \\
GO & 4.093 & 12,5 & 4.052 & 5.406 & 6.319 & 6.092 & 6.984 & 6.018 & 5.938 & 6.605 & 6.809 & 7.253 & 10,5 \\
MS & 2.486 & 7,6 & 3.115 & 3.267 & 4.091 & 3.283 & 3.719 & 4.154 & 4.846 & 4.571 & 4.046 & 5.340 & 7,8 \\
BA & 1.508 & 4,6 & 1.408 & 1.464 & 1.556 & 2.365 & 2.402 & 1.991 & 2.298 & 2.748 & 2.426 & 3.113 & 4,5 \\
MG & 1.439 & 4,4 & 1.391 & 1.951 & 2.335 & 2.661 & 2.937 & 2.454 & 2.418 & 2.566 & 2.751 & 2.902 & 4,2 \\
SP & 1.190 & 3,6 & 1.356 & 1.561 & 1.709 & 1.854 & 1.704 & 1.648 & 1.244 & 1.446 & 1.327 & 1.413 & 2,1 \\
SC & 525 & 1,6 & 534 & 530 & 712 & 642 & 607 & 799 & 1.111 & 946 & 994 & 1.379 & 2,0 \\
TO & 144 & 0,4 & 188 & 244 & 378 & 652 & 905 & 743 & 732 & 894 & 875 & 991 & 1,4 \\
PI & 101 & 0,3 & 128 & 91 & 308 & 388 & 560 & 544 & 485 & 819 & 781 & 868 & 1,3 \\
DF & 93 & 0,3 & 71 & 103 & 120 & 135 & 189 & 146 & 143 & 153 & 155 & 177 & 0,3 \\
\hline
\end{tabular}

\subsection{Evolução da concentração da soja nas microrregiões do Brasil.}

A análise da concentração, tomando-se as microrregiões em relação ao país, revela que a microrregião onde se concentram mais produtores de soja é o Alto do teles Pires (MT), que, em 2000, produzia $8 \%$ de toda soja do país e chegou a representar até $11 \%$ da produção nacional em 2005. Seguida pelo Parecis (MT) (7\% em 2000) com 8\% de participação na produção em 2005. Através desses dados pode-se analisar que o melhor ano para essas duas microrregiões é 2005.

A terceira microrregião produtora do país foi o Sudoeste do Goiás (GO), que representava em 2000 6\% da produção, e em 2010 houve pequena queda passando a representar 4\% da produção, passando para a quarta posição do CR4, deixando a terceira posição no CR4 para a microrregião de Dourados (MS), com 5\% de participação. Entre 2000 e 2010, a produção de soja entre as quatros (CR4) maiores microrregiões houve "ausência de concentração", conforme classificação de Medeiros e Ostroski (2006). Considerando os oito maiores (CR8) apresenta-se nível "baixa concentração" em todos anos analisados, de acordo com a classificação de Medeiros e Ostroski (2006). Entre os doze (CR12) maiores existia em houve também um nível de "baixa concentração".

Tabela 4. Evolução da concentração da produção da soja por Microrregiões Brasileira.

\begin{tabular}{clllllllllll}
\hline Índice & 2000 & 2001 & 2002 & 2003 & 2004 & 2005 & 2006 & 2007 & 2008 & 2009 & 2010 \\
\hline CR4 & $26 \%$ & $25 \%$ & $27 \%$ & $25 \%$ & $24 \%$ & $28 \%$ & $26 \%$ & $24 \%$ & $25 \%$ & $25 \%$ & $23 \%$ \\
CR8 & $37 \%$ & $35 \%$ & $38 \%$ & $34 \%$ & $35 \%$ & $39 \%$ & $35 \%$ & $34 \%$ & $36 \%$ & $35 \%$ & $34 \%$ \\
CR12 & $45 \%$ & $43 \%$ & $46 \%$ & $42 \%$ & $42 \%$ & $45 \%$ & $42 \%$ & $41 \%$ & $43 \%$ & $42 \%$ & $40 \%$ \\
\hline
\end{tabular}


Evolução do nível de concentração e produção da soja no Brasil e Mato Grosso do ano 2000 a 2010

Keite Soares Gazola

Laércio Juarez Melz

Ariel Lopes Torres

Karine Medeiros Anunciato

Em relação à região, pode-se perceber que a região Centro-Oeste foi a que teve a maior concentração de produção nos anos analisados, enfatizando a concentração de produção nessa microrregião (Tabela 4). Em destaque está o Alto do Teles Pires (MT) que teve maior crescimento de participação no mercado da região Centro-Oeste, $3 \%$ de aumento da produção. Toledo (PR) perdeu participação no mercado, passando de 3\% em 2000 para 2\%, em 2010 (Tabela 5).

No CR8, a quinta maior produtora do país, destaca-se a Barreira (BA), que apesar de não apresentar aumento expressivo de participação na produção da soja, possuía 4\% da produção, em 2010. Foi seguida por Canarana (MT), que manteve sua participação estável, que passou de $2 \%$ para $3 \%$ de participação de 2000 e 2010, respectivamente. As demais microrregiões contribuem da seguinte forma: Primavera do Leste (MT), Rondonópolis (MT) e Cruz Alta (RS) ambas em 2010 representavam 2\% da produção nacional, Campo Mourão (PR) e Meia Ponte (GO) com 1\% em 2010.

Por meio da comparação com os níveis de concentração, descritos na metodologia desta pesquisa, poder-se-ia afirmar que a região Centro Oeste apresenta alta concentração. (Tabela 5).

Os indicadores revelam também que há um movimento de ampliação da concentração espacial das atividades, em que tradicionais mesorregiões produtoras reforçam sua posição.

Tabela 5. Identificação dos doze maiores microrregiões produtores de soja do Brasil, 2000-2010, em mil

\begin{tabular}{|c|c|c|c|c|c|c|c|c|c|c|c|c|c|}
\hline Microrregiões & 2000 & $\%$ & 2001 & 2002 & 2003 & 2004 & 2005 & 2006 & 2007 & 2008 & 2009 & 2010 & $\%$ \\
\hline Brasil & 32.821 & 100 & 37.907 & 42.108 & 51.919 & 49.550 & 51.182 & 52.465 & 57.857 & 59.833 & 57.345 & 68.756 & 100 \\
\hline Alto Teles Pires - MT & 2.697 & 8 & 3.065 & 3.855 & 4.352 & 4.612 & 5.630 & 5.275 & 5.108 & 5.813 & 5.750 & 5.893 & 9 \\
\hline Parecis - MT & 2.392 & 7 & 2.631 & 2.912 & 3.096 & 3.119 & 3.902 & 3.304 & 3.313 & 3.573 & 3.584 & 3.531 & 5 \\
\hline $\begin{array}{c}\text { Sudoeste de Goiás - } \\
\text { GO }\end{array}$ & 2.131 & 6 & 2.222 & 2.622 & 2.920 & 2.834 & 2.910 & 2.646 & 2.592 & 2.948 & 3.025 & 3.080 & 4 \\
\hline Dourados - MS & 1.184 & 4 & 1.672 & 1.792 & 2.368 & 1.389 & 1.842 & 2.321 & 2.838 & 2.671 & 2.091 & 3.113 & 5 \\
\hline Barreiras - BA & 1.324 & 4 & 1.231 & 1.280 & 1.359 & 1.997 & 1.992 & 1.653 & 1.897 & 2.294 & 2.022 & 2.600 & 4 \\
\hline Canarana-MT & 620 & 2 & 655 & 849 & 1.019 & 1.162 & 1.450 & 1.345 & 1.368 & 1.595 & 1.636 & 1.893 & 3 \\
\hline Toledo - PR & 938 & 3 & 1.246 & 1.349 & 1.349 & 955 & 1.240 & 906 & 1.363 & 1.440 & 761 & 1.611 & 2 \\
\hline $\begin{array}{c}\text { Primavera do Leste - } \\
\text { MT }\end{array}$ & 820 & 2 & 812 & 1.056 & 1.119 & 1.166 & 1.103 & 933 & 987 & 1.058 & 1.121 & 1.209 & 2 \\
\hline Rondonópolis - MT & 819 & 2 & 751 & 908 & 848 & 1.079 & 1.016 & 863 & 1.031 & 1.123 & 1.188 & 1.242 & 2 \\
\hline Cruz Alta - RS & 606 & 2 & 1.013 & 839 & 1.379 & 784 & 339 & 1.015 & 1.138 & 1.025 & 1.087 & 1.240 & 2 \\
\hline Campo Mourão - PR & 685 & 2 & 771 & 849 & 962 & 939 & 800 & 810 & 1.065 & 948 & 750 & 1.005 & 1 \\
\hline Meia Ponte - GO & 626 & 2 & 555 & 913 & 1.031 & 890 & 996 & 888 & 841 & 844 & 819 & 944 & 1 \\
\hline
\end{tabular}

\subsection{Evolução da concentração da soja nas microrregiões do Mato Grosso.}


Evolução do nível de concentração e produção da soja no Brasil e Mato Grosso do ano 2000 a 2010

Keite Soares Gazola

Laércio Juarez Melz

Ariel Lopes Torres

Karine Medeiros Anunciato

A concentração da produção de soja nas microrregiões do estado do Mato Grosso diminuiu moderadamente entre 2000 e 2010, em relação ao estado do Mato Grosso. O índice CR4 passou de 74\%, em 2000, para 67\%, em 2010 (Tabela 5). Entre as quatro maiores produtoras de soja estão as microrregiões de Alto Teles Pires (MT), com 31\% em 1997 e 2010, Parecis (MT), com 27\% em 2000 e baixando esse percentual em 2010 para 13\%, Canarana (MT), com 7\% em 2000 e 10\% em 2010 e Primavera do Leste (MT), com 9\% em 2000 que também baixou sua produção em relação a produção do estado passando em 2010 para 6\%. Rondonópolis e Sinop em 2010 figuravam entre as quatro maiores microrregiões produtoras do Mato Grosso com 7\% da produção do estado, respectivamente. Entre 2000 e 2010, a produção de soja entre as microrregiões do Mato Grosso foi 'altamente concentrada', conforme classificação de Medeiros e Ostroski (2006). Considerando os oito maiores (CR8) apresenta-se nível 'altamente concentrado' em todos anos analisados, de acordo com a classificação de Medeiros e Ostroski (2006). Entre os doze maiores (CR12) apresenta também um nível 'altamente concentrado'

Tabela 6. Evolução da concentração da produção da soja por Microrregiões do Mato Grosso.

\begin{tabular}{cccccccccccc}
\hline Índice & 2000 & 2001 & 2002 & 2003 & 2004 & 2005 & 2006 & 2007 & 2008 & 2009 & 2010 \\
\hline CR4 & $74 \%$ & $75 \%$ & $74 \%$ & $74 \%$ & $69 \%$ & $68 \%$ & $70 \%$ & $71 \%$ & $68 \%$ & $67 \%$ & $67 \%$ \\
CR8 & $91 \%$ & $91 \%$ & $91 \%$ & $90 \%$ & $89 \%$ & $87 \%$ & $89 \%$ & $90 \%$ & $89 \%$ & $89 \%$ & $88 \%$ \\
CR12 & $99 \%$ & $99 \%$ & $98 \%$ & $98 \%$ & $97 \%$ & $96 \%$ & $96 \%$ & $97 \%$ & $97 \%$ & $96 \%$ & $96 \%$ \\
\hline
\end{tabular}

De um total de 22 microrregiões em todo o Mato Grosso, quatro delas detêm mais da metade da produção de soja no estado (Tabela 7).

Tabela 7. Identificação dos doze maiores microrregiões produtores de soja do Mato Grosso, 2000-2010, em mil

\begin{tabular}{ccccccccccccccc}
\multicolumn{10}{c}{ toneladas, $2000 \mathrm{e} 2010 \mathrm{em} \%$. } \\
\hline Microrregiões & 2000 & $\%$ & 2001 & 2002 & 2003 & 2004 & 2005 & 2006 & 2007 & 2008 & 2009 & 2010 & $\%$ \\
\hline Mato Grosso & 8.774 & 100 & 9.533 & 11.685 & 12.966 & 14.518 & 17.761 & 15.594 & 15.275 & 17.803 & 17.963 & 18.788 & 100 \\
Alto Teles Pires & 2.697 & 31 & 3.065 & 3.855 & 4.352 & 4.612 & 5.630 & 5.275 & 5.108 & 5.813 & 5.750 & 5.893 & 31 \\
Parecis & 2.392 & 27 & 2.631 & 2.912 & 3.096 & 3.119 & 3.902 & 3.304 & 3.313 & 3.573 & 3.584 & 3.531 & 19 \\
Canarana & 620 & 7 & 655 & 849 & 1.019 & 1.162 & 1.450 & 1.345 & 1.368 & 1.595 & 1.636 & 1.893 & 10 \\
Primavera do Leste & 820 & 9 & 812 & 1.056 & 1.119 & 1.166 & 1.103 & 933 & 987 & 1.058 & 1.121 & 1.209 & 6 \\
Rondonópolis & 819 & 9 & 751 & 908 & 848 & 1.079 & 1.016 & 863 & 1.031 & 1.123 & 1.188 & 1.242 & 7 \\
Sinop & 83 & 1 & 177 & 257 & 359 & 639 & 1.032 & 961 & 798 & 974 & 1.173 & 1.225 & 7 \\
Arinos & 132 & 2 & 171 & 329 & 341 & 504 & 727 & 713 & 613 & 987 & 803 & 878 & 5 \\
Tesouro & 431 & 5 & 407 & 486 & 489 & 594 & 624 & 478 & 579 & 651 & 653 & 674 & 4 \\
Alto Araguaia & 420 & 5 & 420 & 473 & 533 & 480 & 552 & 413 & 346 & 438 & 395 & 424 & 2 \\
Aripuanã & 147 & 2 & 195 & 235 & 268 & 340 & 489 & 360 & 249 & 465 & 425 & 421 & 2 \\
Paranatinga & 44 & 1 & 58 & 53 & 121 & 216 & 267 & 191 & 229 & 342 & 407 & 453 & 2 \\
Tangará da Serra & 80 & 1 & 74 & 93 & 102 & 135 & 231 & 172 & 145 & 163 & 158 & 160 & 1 \\
\hline
\end{tabular}


Evolução do nível de concentração e produção da soja no Brasil e Mato Grosso do ano 2000 a 2010

Keite Soares Gazola

Laércio Juarez Melz

Ariel Lopes Torres

Karine Medeiros Anunciato

Nas quatro maiores microrregiões houve concentração até o ano de 2004 a soja em relação a produção do estado, a partir do ano de 2005 houve a desconcentração. Esta desconcentração foi mais evidente pois passaram de 74\%, em 2000, para 69\%, em 2005. A partir de 2005 microrregiões como Sinop (6\%), Arinos (4\%) e Tesouro (5\%) aumentaram sua produção fazendo com que houvesse uma desconcentração na produção dos CR4. Alto Paraguai teve uma queda de produção em 2000 representava 5\% da produção estado em 2010 foi para $2 \%$, Aripuanã obteve produção estável de $2 \%$ com pico em 2005 e representou $3 \%$ da produção do estado. Paranatinga nos anos analisados cresceu em 1\% sua produção em relação ao estado. A microrregião de Tangara da Serra manteve-se com seu 1\% de produção nos anos analisados.

\subsection{Evolução da concentração dos maiores produtores de soja do estado do Mato Grosso}

Ao analisar os dados do aumento de produção da soja por cidade nota-se que Canarana e Sorriso mantiveram-se com o nível produção estável nestes dez anos (tabela 8). Entre 2000 e 2010, a produção de soja entre as quatro maiores cidades do Mato Grosso foi 'baixa concentração', conforme classificação de Medeiros e Ostroski (2006).. Considerando os oito maiores (CR8) nos anos analisados apresenta-se nível 'concentração moderada' em todos anos analisados, de acordo com a classificação de Medeiros e Ostroski (2006). Entre os dezesseis maiores (CR16) apresenta nível "altamente consertado".

Tabela8. Evolução do grau de concentração por cidades do estado do Mato Grosso.

\begin{tabular}{cccccccccccc}
\hline Índice & 2000 & 2001 & 2002 & 2003 & 2004 & 2005 & 2006 & 2007 & 2008 & 2009 & 2010 \\
\hline CR 4 & 37,53 & 37,21 & 35,11 & 34,29 & 32,27 & 30,92 & 32,43 & 32,81 & 31,07 & 32,07 & 32,03 \\
CR 8 & 61,67 & 60,37 & 56,51 & 56,68 & 53,24 & 52,10 & 53,64 & 53,18 & 52,54 & 52,67 & 52,21 \\
CR 16 & 89,82 & 88,55 & 84,81 & 83,54 & 82,00 & 78,47 & 80,48 & 81,09 & 79,82 & 79,88 & 80,26 \\
\hline
\end{tabular}

Os quatro maiores produtores de soja em 2000 é Sorriso (13,54\%),Campo Novo do Parecis $(9,33 \%)$, Sapezal 7,59 e Canarana (7,06\%). Houve em 2010 mudanças entre os quatro maiores produtores de soja no estado do Mato Grosso, Canarana $(10,08 \%)$ passou a ser o 
Evolução do nível de concentração e produção da soja no Brasil e Mato Grosso do ano 2000 a 2010

Keite Soares Gazola

Laércio Juarez Melz

Ariel Lopes Torres

Karine Medeiros Anunciato

maior produtor, em seguida Sorriso (9,65\%), Sinop (6,52\%) e Sapezal (5,77\%). Com esses valores fica evidente o grau de desconcentração da produção da soja em MT.

Em 2010 Canarana teve a maior produção de soja do estado do Mato Grosso, teve evolução de 3,5\% de 2000 para 2010 (Tabela 9). Sorriso em 2010, foi o maior produtor de soja brasileira devido a sua região ser altamente modernizada e especializada no ramo, diante desse fator manteve-se com a produção de grãos estável nos anos analisados, em 2000 representava 13,59\% da produção do estado e em 2010 esse percentual era de 9,65\% (Tabela9).

Sinop correspondia em 2000 a 0,94 \% da produção do estado, em 2010 fechou o ano com 6,52\% da produção e assim fazendo parte dos CR4. Apenas Sorriso e Canarana mantiveram-se no CR 4 durante os anos analisados (Tabela 9).

Sapezal em 2010 era responsável por 5,77\% da produção do estado, em 2005 foi seu melhor ano em relação a produção (6,57\%) (Tabela 9). Nova Mutum em 2010 teve a quinta maior produção com 5,53\% da produção do estado (Tabela 9).

Tabela 9. Identificação dos doze maiores cidades produtoras de soja do Mato Grosso, 2000-2010, em mil toneladas, 2000 e 2010 em \%.

\begin{tabular}{|c|c|c|c|c|c|c|c|c|c|c|c|c|c|}
\hline Municípios & 2000 & $\%$ & 2001 & 2002 & 2003 & 2004 & 2005 & 2006 & 2007 & 2008 & 2009 & 2010 & $\%$ \\
\hline Mato Grosso & 8.774 & 100 & 9.533 & 11.685 & 12.966 & 14.518 & 17.761 & 15.594 & 15.275 & 17.803 & 17.963 & 18.788 & 100 \\
\hline Canarana & 620 & 7 & 655 & 849 & 1.019 & 1.162 & 1.450 & 1.345 & 1.368 & 1.595 & 1.636 & 1.893 & 10 \\
\hline Sorriso & 1.188 & 14 & 1.269 & 1.482 & 1.600 & 1.688 & 1.805 & 1.790 & 1.663 & 1.794 & 1.841 & 1.814 & 10 \\
\hline Sinop & 83 & 1 & 177 & 257 & 359 & 639 & 1.032 & 961 & 798 & 974 & 1.173 & 1.225 & 7 \\
\hline Sapezal & 666 & 8 & 774 & 872 & 924 & 955 & 1.167 & 932 & 1.011 & 1.062 & 1.113 & 1.086 & 6 \\
\hline Nova Mutum & 493 & 6 & 490 & 585 & 706 & 856 & 1.068 & 962 & 971 & 1.082 & 1.049 & 1.039 & 6 \\
\hline $\begin{array}{c}\text { Campo Novo do } \\
\text { Parecis }\end{array}$ & 818 & 9 & 849 & 900 & 903 & 880 & 1.071 & 869 & 894 & 991 & 967 & 1.006 & 5 \\
\hline Diamantino & 576 & 7 & 594 & 657 & 747 & 732 & 918 & 795 & 796 & 871 & 879 & 868 & 5 \\
\hline Nova Ubiratã & 252 & 3 & 156 & 388 & 373 & 483 & 579 & 631 & 576 & 718 & 734 & 786 & 4 \\
\hline $\begin{array}{l}\text { Lucas do Rio } \\
\text { Verde }\end{array}$ & 528 & 6 & 557 & 572 & 698 & 528 & 744 & 684 & 624 & 759 & 704 & 757 & 4 \\
\hline Querência & 46 & 1 & 64 & 88 & 151 & 221 & 336 & 461 & 450 & 534 & 574 & 710 & 4 \\
\hline $\begin{array}{l}\text { Primavera do } \\
\text { Leste }\end{array}$ & 522 & 6 & 567 & 686 & 753 & 737 & 685 & 550 & 620 & 656 & 660 & 703 & 4 \\
\hline Tesouro & 431 & 5 & 407 & 486 & 489 & 594 & 624 & 478 & 579 & 651 & 653 & 674 & 4 \\
\hline Itiquira & 352 & 4 & 341 & 408 & 366 & 501 & 460 & 372 & 513 & 540 & 540 & 600 & 3 \\
\hline Ipiranga do Norte & 0 & 0 & 0 & 0 & 0 & 0 & 463 & 406 & 374 & 475 & 493 & 535 & 3 \\
\hline Campo Verde & 298 & 3 & 245 & 369 & 366 & 429 & 419 & 383 & 367 & 402 & 461 & 506 & 3 \\
\hline Campos de Júlio & 317 & 4 & 393 & 456 & 492 & 499 & 628 & 592 & 475 & 522 & 529 & 457 & 2 \\
\hline
\end{tabular}

Campo Novo dos Parecis nos primeiros anos estava como o segundo maior produtor acabou perdendo essa colocação nos anos seguintes, mesmo com essa pequena queda de 3,97\% que segundo o IBGE as condições climáticas desfavoráveis (a falta de chuva) é um dos motivos para a queda de produção de algumas regiões em proporção a produção dos anos analisados, Campo Novo sempre manteve seu nível de produção constante no ano de 2003 foi 
Evolução do nível de concentração e produção da soja no Brasil e Mato Grosso do ano 2000 a 2010

Keite Soares Gazola

Laércio Juarez Melz

Ariel Lopes Torres

Karine Medeiros Anunciato

para o quarto, perdendo para, Sinop e Nova Mutum que a partir do ano de 2006 passaram a fazer parte do grupo dos CR4 maiores produtores de soja do País (Tabela 9).

Diamantino teve uma queda em média de 1,95\% de 2000 até 2010, mas sua produção foi suficiente para manter a cidade dentro do grupo do CR8 (Tabela 9). Nova Ubiratã uma pequena cidade no norte do Mato Grosso que em 2000 passou a fazer parte do CR16, teve um queda em 2001, mas sua produção foi aumentando gradativamente no decorrer dos anos, chegando em 2010 como a nona produtora de soja com 4,18\% da produção do Estado (Tabela 9).

A cidade de Lucas do Rio Verde, apesar da variação durante o período avaliado, teve sua produção acima de 500.000 sacas/ano, e com isso se mantem entre os maiores produtores de soja.

Já a cidade de Querência teve crescimento muito grande, em 2000 produzia $0,52 \%$ referente a produção do estado, em 2010 já passou a responder por 3,77\% (Tabela 9). A produção em Primavera do Leste passou por algumas oscilações, mas em 2010 foi a décima primeira produtora de soja do estado com 3,74\% (Tabela 9).

Tesouro que vem como a decima segunda em produção do estado em 2010 teve um crescimento de 2000 para 2010 de $45 \%$ (Tabela 9). Itiquira teve crescimento de quase 50\%, em 2010, e 3,19\% da produção do estado foi nesta cidade (Tabela 9).

Para a cidade de Ipiranga do Norte é possível constatar uma mudança súbita em seu quadro de produção. A partir de 2005 a cidade tem aumentado sua produção e em 2010 entrou no CR16 com produtividade de 2,84\% comparada ao estado (Tabela 9).

Campo Verde aumentou sua produção nesses anos passando de 297.635 para 506.002 sacas em 2010 (Tabela 9). A cidade de Campos de Júlio teve sua maior produção no ano de 2005 representando 3,53\% da produção do estado, em 2010 passou a fazer parte do CR16 com $2,43 \%$ da produção (Tabela 9).

\section{CONCLUSÃO}

Concluiu-se que houve desconcentração da produção de soja nos anos analisados. Os estados se mantiveram entre os quatro maiores produtores do Brasil entre 2000 e 2010. Entretanto, houve uma desconcentração de produção nos estados a partir de 2004. Os 12 maiores estados brasileiros produtores de soja representaram $98 \%$ da produção brasileira no 
Evolução do nível de concentração e produção da soja no Brasil e Mato Grosso do ano 2000 a 2010

Keite Soares Gazola

Laércio Juarez Melz

Ariel Lopes Torres

Karine Medeiros Anunciato

ano de 2010. Nas microrregiões Brasileiras houve uma desconcentração de produção nos anos analisados, os 12 maiores produtores não chegam a representar $50 \%$ da produção do país.

Houve desconcentração da produção de soja nos municípios do estado do Mato Grosso devido a entrada de novos municípios entre os 16 maiores produtores de soja, como Ipiranga do Norte que a partir de 2006 passou a fazer parte do CR16. A hipótese levantada sobre a desconcentração foi confirmada pois houve a entrada de novos municípios nos CR16. Adicionalmente foi possível identificar que os municípios de Sorriso e Canarana figuraram entre os 4 maiores do MT durante os 10 anos analisados.

\section{REFERÊNCIAS}

DE LA CRUZ. Betty Clara Barraza. Contribuição para a análise da competitividade da soja em grãos: uma aplicação do modelo de equilíbrio espacial ao estado de Tocantins. Tese (Doutorado em Engenharia Industrial) - Pontifícia Universidade Católica do Rio de Janeiro, Rio de Janeiro, 2007. Disponível em: 〈http://www2.dbd.pucrio.br/pergamum/tesesabertas/0212246_07_cap_02.pdf $>$.

AGRICOMMODITYPRICES. Disponível em:

<http://www.agricommodityprices.com/soybean.php>.

AVILA,Gustavo Pereira. Fundamentos, Situação atual e perspectiva da soja. Disponível em: <http://www.slideshare.net/avilagustavo/fundamentos-situao-atual-e-perspectiva-da-soja .

BAIN, Joe S. Industrial organization. New York: John Wiley \& Sons, Inc., 1959.

BEUREN, Ilse Maria. Como elaborar trabalhos monográficos em contabilidade: teoria e prática. São Paulo: Atlas, 2003.BOYLE, Stanley. Industrial organization: an empirical approach. New York: Holt, Rineheart and Winston, 1972 (apud Brumer, 1981).

BRAGA, Helson , MASCOLO, João. Mensuração da concentração industrial no BrasilMinistério do Desenvolvimento e Indústria e Comércio Exterior. Balança Comercial brasileira. Disponível em: 〈http://www.desenvolvimento.gov.br/sitio/interna/interna〉.

CEAGRO, Competitividade em Sistemas Agroindustriais. Disponível em: $<$ http://ceragro.iica.int/obsevatorio/Lists/OUTRAS\%20METODOLOGIAS\%20DE\%20ACO MPANHAMENTO\%20DE\%20CADEIAS\%20P/Attachments/5/Competitividade $\% 20 \mathrm{em} \% 20$ Sistemas\%20Agroindustriais\%20-\%20Metodologia\%20e\%20Estudo\%20de\%20Caso.pdf >. 
Evolução do nível de concentração e produção da soja no Brasil e Mato Grosso do ano 2000 a 2010

Keite Soares Gazola

Laércio Juarez Melz

Ariel Lopes Torres

Karine Medeiros Anunciato

CONAB - Companhia Nacional de Abastecimento. Séries históricas de produtividade de grãos. Disponível em: 〈http://www.conab.gov.br〉.

CONCENTRAÇÃO E COMPETITIVIDADE: ASPECTOS TEÓRICOS. Disponível em: < http://www.eps.ufsc.br/disserta98/leite/cap3.htm>.

ECOA. Disponível em:

$<$ http://www.riosvivos.org.br/Noticia/A+soja+no+Brasil+Central+++Expansao+agricola+no+ Cerrado+brasileiro/1188>.

EMBRAPA. Empresa Brasileira de Pesquisa Agropecuária. Soja em números (safra 2010/2011). Disponível em:

<http://www.cnpso.embrapa.br/index.php?cod_pai=2\&op_page=294>. Acesso em: 27 fev. 2012.

.Desenvolvimento, Mercado e Rentabilidade da Soja Brasileira. Disponível em: <http://www.cnpso.embrapa.br/download/CT74_eletronica.pdf>.

Tecnologias de produção de soja região central do Brasil 2003.Disponível em :

$<$ http://sistemasdeproducao.cnptia.embrapa.br/FontesHTML/Soja/SojaCentralBrasil2003/imp ortancia.htm>.

FEDRIZZI, Luiz Carlos. A soja como fator de competitividade no Mercosul. Disponível em : <http://www.fee.tche.br/sitefee/download/jornadas/2/e13-10.pdf >.

GAAMAWEB. Disponível em : <http://www.dag.uem.br/gaama/trans4.htm>.

GROPPELLI, A.A., NIKBAKHT, E. Administração Financeira. Tradução Célio Knipel Moreira. 2. Ed. São Paulo.

GUANZIROLI, Carlos Enrique. Agronegócio no Brasil Perspectivas e Limitações. Disponível em: 〈http://www.uff.br/econ/download/tds/UFF_TD186.pdf>

IBGE - Instituto Brasileiro de Geografia e Estatística. Disponível em:<http://www.ibge.gov.br/home/presidencia/noticias/noticia_visualiza.php?id_noticia=635 \&id_pagina=1>. Acesso em 14 mar.2012 
Evolução do nível de concentração e produção da soja no Brasil e Mato Grosso do ano 2000 a 2010

Keite Soares Gazola

Laércio Juarez Melz

Ariel Lopes Torres

Karine Medeiros Anunciato

- Instituto Brasileiro de Geografia e Estatística. Disponível em:

$<\mathrm{http}: / / \mathrm{www} \cdot$ sidra.ibge.gov.br/bda/tabela/listabl.asp?c=1612\&n=0\&u=0\&z=t\&o=11\&i=P>.

- Instituto Brasileiro de Geografia e Estatística. Tabela. Disponível em:

Instituto Brasileiro de Geografia e Estatística

$<\mathrm{http} / /$ www.sidra.ibge.gov.br/bda/tabela/listabl.asp? $\mathrm{z}=\mathrm{t} \& \mathrm{o}=11 \& \mathrm{i}=\mathrm{P} \& \mathrm{c}=1612>$. Acesso em11mar 2012.

IMA MT - Instituto Mato-grossense de Algodão. Disponível em:

<http://www.imamt.com.br/home/noticia/442>.

Lazzarotto, J. J. , Hirakuri, M. H. Evolução e Perspectivas de Desempenho Econômico Associadas com a Produção de Soja nos Contextos Mundial E Brasileiro. Disponível em: <http://www.infoteca.cnptia.embrapa.br/bitstream/doc/887037/1/Doc3192ED1.pdf>.

LOPES,H. C., MARION FILHO, P. J. Mudança Estrutural e Competitividade. Disponível em: 〈http://www.fee.tche.br/3eeg/Artigos/m17t01.pdf> . Acesso em 14 mar.2012

MARAFON, G.J. A dimensão espacial do complexo agroindustrial soja no Estado do Rio Grande do Sul. Rio de Janeiro: UFRJ, 1998. Tese (Doutorado em Geografia), Universidade Federal do Rio de Janeiro, 1998. Disponível em:

<http://www.fee.tche.br/sitefee/download/jornadas/2/e13-10.pdf >.

MAROUELLI, Rodrigo Pedrosa. O Desenvolvimento sustentável da Agricultura no Cerrado Brasileiro. Disponível em:

http://www.iica.org.br/Docs/Publicacoes/PublicacoesIICA/RodrigoMarouelli.pdf.

MEDEIROS, Natalino Henrique; OSTROSKI, Diane Aparecida. Competitividade e concentração de mercado: uma análise da avicultura nas mesorregiões oeste e sudoeste paranaense. In: Congresso da SOBER, XLIV, Fortaleza, 2006.

MELZ, Laércio Juarez Melz. Análise da concentração espacial dos alojamentos de frangos no Brasil. Disponível em <https://sites.google.com/a/unemat.br/cictga/pesquisa/publicacoes>.

MERCOPRESS. Disponível em:<http://en.mercopress.com/2011/09/17/mercosurconsolidates-as-leading-soybean-region-with-52-of-world-s-production>. 
Ministérios da Agricultura. Disponível em :

http://www.agricultura.gov.br/vegetal/culturas/soja.

NUTRISOY. Disponível em :

<http://www.nutrisoy.com.br/htmls/dicas/perspectivas.htm\#artigo>.

PEREZ, Mariana. País chamado Mato Grosso. Diário de Cuiabá. Disponível em: <http://www.diariodecuiaba.com.br/detalhe.php?cod=404850>.

RESENDE, M. Medidas de concentração industrial: uma resenha. Análise

RESENDE, Marcelo; BOFF, Hugo. Concentração industrial. In: KUPFER, David; HASENCLEVER, Lia. Economia indústria: fundamentos teóricos e práticos no Brasil. Rio de Janeiro: Elsevier, 2002.

SCHMIDT ,Cristiane Alkmin Junqueira. Índices de Concentração1.Disponivel em: 〈www.seae.fazenda.gov.br/central_documentos/...1/doctrab13.pdf >.

SOARES, Thelma Shirlen. Concentração no consumo de madeiras e estrutura de mercado do setor moveleiro do município de Ubá/MG. Disponível em:<http://www.revista.inf.br/florestal07/pages/resenhas/nota03.pdf $>$.

SONOTICIAS.AGRONOTICIAS. Disponível em:

<http://www.sonoticias.com.br/agronoticias/mostra.php?id=48984>.

TINK FIN. Disponível em: 〈http://www.thinkfn.com/wikibolsa/IHH> . Acesso em 14 mar.2012

Tudo sobre a Soja. Disponível em: <http://soja.tudosobre.org/>. Acesso em 04 mar.2012

ZUCHELLI, Jean Michel. Viabilidade econômica da produção de soja, com sucessão.

Disponível em

:<http://www.upis.br/pesquisas/pdf/agronomia/2010_3/Jean_Michel_Zuchelli_AC_Viabilidad e_econ\%C3\%B4mica_produ\%C3\%A7\%C3\%A3o_soja_sucess\%C3\%A3o_Brachiaria_ruzizi ensis_regi\%C3\%A3o_Sorriso_MT..pdf>. 